
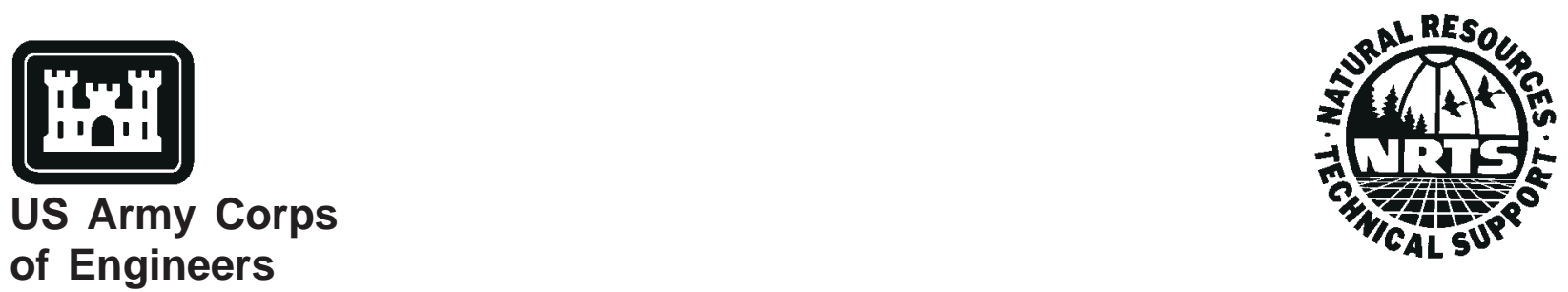

\title{
Native American Recreation at Corps Projects: Results of Six Focus Groups
}

\author{
Robert A. Dunn, U.S. Army Engineer Waterways Experiment Station,
} and Dr. Timothy D. Feather, Planning and Management Consultants, Ltd.

\section{Purpose}

Research is being conducted at the Waterways Experiment Station (WES), under the Recreation Research Program (RRP), to determine the existing and future ethnic group use of Corps of Engineers operating projects and to help identify their recreation preferences and needs. This information will be used by decision-makers in project planning and operations.

During a 3-year period (fiscal years 1997-99), four ethnic minority groups will be studied: Native-Americans, African-Americans, Asian-Americans, and Hispanics. This research effort is in response to Executive Order 12862, "Setting Customer Service Standards," and Executive Order 12898, "Federal Actions to Address Environmental Justice in Minority Populations and Low-Income Populations."

Specific objectives of this research are to compare present Corps users to general population proportions; identify relevant information, policies, and studies (from the Corps and other agencies) on ethnic and nontraditional use of Corps projects; determine existing and future ethnic group use of Corps projects and determine recreation preferences and needs; evaluate existing and future needs of ethnic groups; and provide a summary of findings, along with guidance that incorporates considerations for ethnic users in planning and operations decisions.

Little research has been done on recreation research among Native American groups (see McDonald and McAvoy 1997). Initial research, conducted under the RRP work unit "Ethnic Culture and Corps Recreation Participation," identified the need for primary source data on Native American recreational habits and preferences.

In an extensive literature review, Gramann (1996) recommended that, in lieu of administering a traditional survey instrument, a series of focus groups would be more 
effective in obtaining a representative sampling of Native American recreational habits and preferences. To this end, six focus group meetings were conducted during summer 1997 in two Corps Districts with high Native American visitation to their projects (Figure 1). This technical note summarizes the findings derived from the focus group meetings and discusses the implications for the Corps' working relations with Native American customers. Research results for all four minority groups will be included in a WES Technical Report, scheduled for completion in fiscal year 1999.

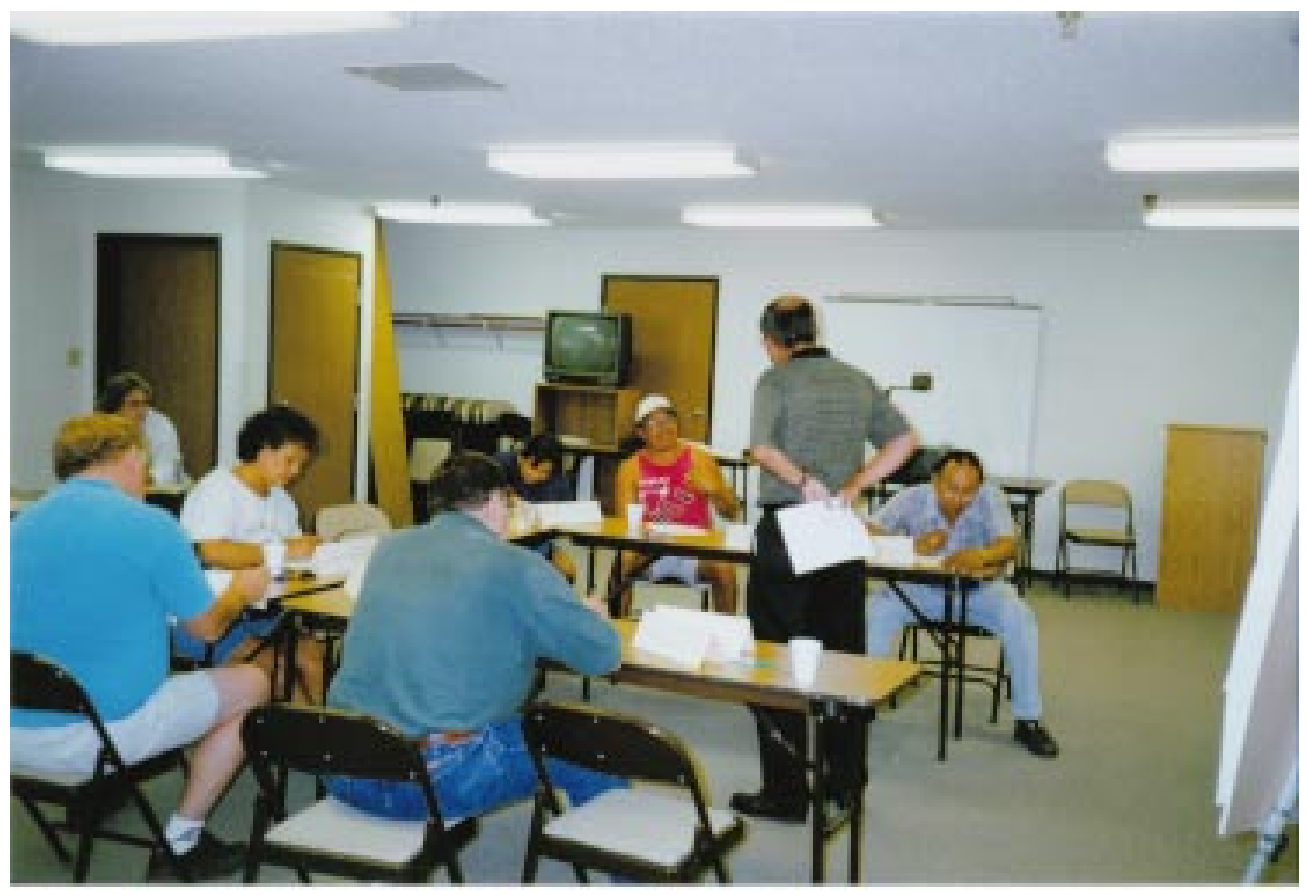

Figure 1. Focus group participants offered constructive and enthusiastic input to the discussion of Native American recreation needs

\section{Background}

To help organize focus groups among the Native American tribes, WES requested the assistance of Omaha District's Tribal Coordinator, Mr. Dave Vader, and Tulsa District Archaeologist Dr. Frank Winchell and his sociologist colleague, Dr. Edwin Rossman. Meetings of the focus groups were to be facilitated and recorded by WES's contractor, Planning and Management Consultants, Ltd. (PMCL), of Carbondale, IL. Dr. Tim Feather served as the PMCL project manager and recorded the three South Dakota meetings. Dr. Dale Brown of Southern Illinois University and PMCL facilitated all six focus groups. Mr. Don Capan of PMCL recorded the three Oklahoma meetings.

A planning meeting for the Omaha and Tulsa District tribal coordinators and the contractors was held at WES on May 20, 1997. The participants finalized the logistical planning for the meetings and tested the proposed design of the focus group by participating in a dry run. The Oklahoma meetings were subsequently held on June 23-25, 1997, and the South Dakota meetings were held July 21-23, 1997. Descriptions of each of the six focus group meetings are provided in subsequent sections of this technical note. 


\section{What is a Focus Group?}

Krueger (1988) provides a thorough review of the development of the focus group approach in applied research. He defines a focus group as "a carefully planned discussion designed to obtain perceptions on a defined area of interest in a permissive, nonthreatening environment. It is conducted with approximately seven to ten people by a skilled interviewer. The discussion is relaxed, comfortable, and often enjoyable for participants as they share their ideas and perceptions. Group members influence each other by responding to ideas and comments in the discussion."

Focus groups evolved from nondirective individual interviewing in the 1930s when social scientists began to have doubts about the accuracy of traditional informationgathering methods. They were concerned about the excessive influence of the interviewer and the limitations of predetermined closed-ended questions. Nondirective interviews used open-ended questions and allowed individuals to respond without setting boundaries or providing clues to potential response categories. They allowed the subjects ample opportunity to explain their responses and to share experiences and attitudes, as opposed to the structured and directive interview that is dominated by the interviewer (Krueger 1988).

Since the end of World War II, most applications of focus group interviewing have been in market research. Focus group interviews allow producers, manufacturers, and sellers to understand the thinking of the consumers they wish to reach with their product. Focus group interviews are now regarded by many manufacturers as a crucial step in shaping the marketing strategy for their products. Krueger (1988) provides several examples of products that have undergone major revisions in manufacturing, packaging, or advertising due to findings of focus groups. In the world of marketing research, focus group interviews are widely accepted because they produce believable results at a reasonable cost. In the larger sphere of social scientists, planners, and educators, focus group interviewing seems appropriate when the goal is to explain how people regard an experience, idea, or event.

The focus group interview is a qualitative, rather than quantitative, research tool. Does this make it less credible? Not according to Krueger (1988), who notes:

For several decades, the pendulum of evaluation research has swung to the quantitative side with primary attention to experimental designs, control groups, randomization. This sojourn with numbers has been beneficial in that we have gained in our experimental sophistication, but it also nurtured a desire for more understanding of the human experience. Too often the quantitative approaches were based on assumptions about people, about things, or about reality in general that were not warranted.

In their recent overview of Native American leisure research, McDonald and McAvoy (1997) have also noted that "given (Native Americans') preference for the spoken word, the spiritual nature of interaction with people and the land, the sense of inter-relationships, and the meaning given to sense of place, it appears that qualitative methods will be more successful at answering the (research) questions discussed here."

If Corps professionals want to improve their programs and services, they must know how their customers view the existing programs. Focus groups can provide reliable and 
accurate information about perceptions, feelings, and attitudes, allowing Corps managers to see reality from the customer's point of view. The disparity between the world view and the life experiences of Corps' decision-makers and their Native American customers made the focus group approach particularly appropriate.

\section{Oklahoma Meetings}

Three focus group meetings were held in the Tulsa District. The first was held in Muskogee, OK, on June 23, 1997, at the Bureau of Indian Affairs (BIA) office. The second was held at the Pawnee Tribal Headquarters on June 24, 1997. The third meeting, on June 25, was conducted at Anadarko, OK, at the BIA Agency office. All three meetings were organized by Drs. Frank Winchell and Ed Rossman and were facilitated and recorded by PMCL. The major findings and results of each focus group are presented below. The opinions expressed will be attributed to the tribes represented and not to individuals.

Detailed summary notes of each of the meetings were prepared by PMCL; copies are available from Mr. Robert Dunn, (601) 634-2380, dunnr@mail.wes.army.mil.

\section{Muskogee Focus Group}

Arrangements for securing the meeting location and inviting the attendees were handled by Drs. Winchell and Rossman of the Tulsa District and Mr. Ben Barnette of the Muskogee office of the BIA. Six eastern (Oklahoma) tribes were invited to participate. Of these, three Native American tribes were represented: the Delaware, the Choctaw, and the Chickasaw.

This first meeting, and all subsequent focus groups, was structured around two questions:

(1) What outdoor recreation/leisure activities do Native Americans like to pursue?

(2) What are some of your recreation/leisure experiences at Corps projects and what improvements or management actions could be taken to enhance those activities?

At the outset of the meeting the participants were asked to create a picture or list a series of words that represented important aspects of Native American recreation/leisure at Corps projects, existing or desired. The Muskogee participants were very willing to offer information and generally appeared to have a high level of education and adoption/appreciation of some traditional Euro-American values. Of the six focus groups, they showed the highest degree of cultural assimilation (acculturation) to mainstream American recreational activities. The tone of the Muskogee meeting was enthusiastic and constructive, and throughout the 2.5-hr meeting, the participants appeared very comfortable with the focus group approach and the questions that were asked. This was verified by the participant responses to the evaluation given at the end of focus group.

The primary findings of the Muskogee focus group were as follows:

- There is a need to integrate educational opportunities and recreational experiences for Native Americans. Native Americans want to pass on their language and culture to their children and to familiarize Euro-Americans with their culture. Interpretive signs, 
displays, and living history activities at Corps projects, developed in consultation with resident Indian tribes, would be enthusiastically accepted by Native Americans.

- Native Americans in eastern Oklahoma like to pursue a number of recreational activities, including swimming, fishing, camping, hiking, picnicking, hunting, gospel singing, and Indian dancing. While many of these are also typical for Euro-American family groups, Native Americans typically recreate in much larger social groups (50 to 200 people). Most Corps picnic areas are not designed to accommodate such large groups (Figure 2).

- Organized dancing events/competitions, known as powwows, which can be ceremonial/religious or purely social in nature, are the focus of much of the social life of Native Americans. Generally the social powwows are intertribal, with one tribe hosting, and are open to the public. With few exceptions, Euro-Americans are welcome participants. Corps projects willing to provide facilities, such as dance arbors and camping areas that could be reserved/leased by the hosting tribe, would be much more "Indian-friendly" and could expect higher Native American visitation.

- Most recreational activities of Native Americans are driven by their youth. The education of children and teens by elder Native Americans through the use of traditional Indian recreational activities (e.g., powwows) appears to be an essential component of their culture. However, some noneducational activities, such as basketball and volleyball, are also becoming more popular at tribal centers in Oklahoma.

- The major challenges to Native American recreation include the need for block reservations at campsites, adequate toilet/shower facilities, sufficient beach space, larger fire pits, high user fees, access for the elderly, the racist attitudes of some personnel (gate attendants) at Corps projects, and the need for private areas for ceremonial/ religious activities. Corps project managers willing to work with resident Indian

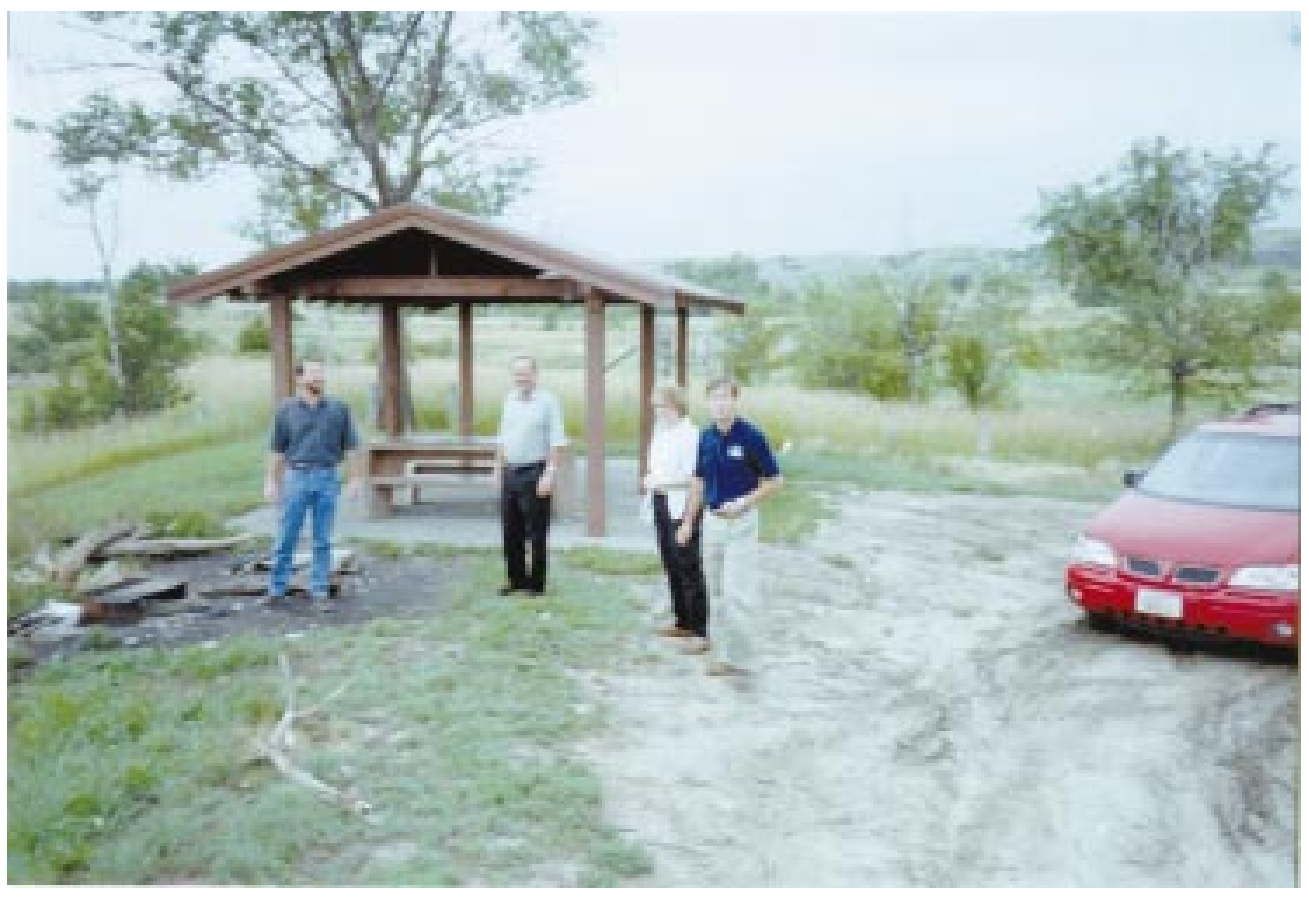

Figure 2. Many public-use areas, such as this one at Lake Sharpe, South Dakota, offer very limited capacity for Native American recreation events 
groups on these problems can expect a dramatic increase in Indian visitation. Many of these problems stem from the larger recreational group size of Native Americans. The racist attitudes were not attributed to uniformed Corps personnel, but only to contract ("Mom and Pop") gate attendants. The user fee issue was raised in each of the six focus groups. The waiver of these fees for Native Americans is a thread running through each of the subsequent focus groups.

- The construction of an amphitheater or a dance arbor at a Corps project that could be reserved by Native American groups during the year was suggested as a concrete way to better support Native American recreation (and Euro-American attendance, where appropriate). Use of a scheduling calendar for these types of facilities would minimize scheduling conflicts.

- Other activities, such as sporting tournaments, physique contests, and boat races, were suggested as additional recreational activities that could be sponsored by the Corps or held at Corps lakes under tribal sponsorship to attract Native Americans in this part of Oklahoma. Great concern was expressed about personal watercraft (such as jet-skis) posing safety hazards on Corps lake. These comments are reflective of the high degree of acculturation of the "civilized" tribes of eastern Oklahoma. The term "civilized" has been traditionally used for the five southeastern tribes (Cherokee, Choctaw, Creek, Chickasaw, and Seminole), which were forcibly removed by the U.S. Army in the 1830s during the "Trail of Tears" episode.

\section{Pawnee Focus Group}

The focus group meeting conducted on June 24, 1997, at the Pawnee Tribal Headquarters in Pawnee, OK, was organized by Dr. Frank Winchell of the Tulsa District and Mr. Monty Matlock, Director of Environmental Protection for the Pawnee Tribe. Representatives from seven tribes residing in north Oklahoma were invited. One of the invited tribes (Delaware) chose to attend the Muskogee focus group. The remaining tribes chose not (or were unable) to attend. Only the Pawnee and Cherokee tribes were represented at the meeting.

As in the first focus group, the "visioning activity" preceded the main discussion. This activity required the participants to create a picture or list a series of words that represented important aspects of Native American recreation at Corps projects, either existing or desired. The participants were willing to offer information during the focus group at the request of the discussion facilitator. Participants generally appeared to have attained at least a high school education.

There was a discernible split in the group between Native Americans who were members of the Native American Church and those who were members of Christian churches and had accepted most Euro-American values. Much of the discussion centered on the water-based recreation provided by a former Work Projects Administration (WPA) project (Pawnee Lake) built for the town of Pawnee that had been closed within the last 3 years. This facility was visited by the WES team following the focus group. The meeting lasted approximately $2 \mathrm{hr}$, and during that time the group appeared to be fairly comfortable with the focus group approach and the questions that were asked. This was also verified by the participant responses to the evaluation form completed at the end of the meeting. The tone of the meeting was one of cautious cooperation. The participants generally seemed less familiar with Corps projects than those who had participated in the Muskogee meeting. 
The primary findings of the Pawnee focus group are summarized below.

- Education is an important activity to integrate with recreational activities for the young. Young people drive Native American recreation. Interpretive programs at Corps projects dealing with natural and cultural (Native American) resources are especially desirable.

- Recreational activities enjoyed by most Native Americans include fishing, swimming, hiking, picnicking, camping, hunting, boating, softball, and basketball. The major difference (from Euro-Americans) is that Native Americans prefer to recreate in larger extended family groups. Family picnicking would typically involve groups of 40 or more people. Shade is critical for the enjoyment of a recreation area. The popularity of Pawnee Lake (closed WPA project) was largely due to the trees surrounding the lake which provide shade during the hot summer months. Toilet and shower facilities need to be larger, and campground accommodations such as large fire pits and consecutive campsites should be made available at Corps projects in "Indian country" (parts of the United States with large Native American populations).

- Corps campground fees are seen as too costly. In some cases, Native Americans' refusal to pay is based more on principle than cost. The possibility of waiving campground and day-use fees for Native Americans should be explored.

- There are few local Corps projects in northern Oklahoma that Native Americans can reach. Economic difficulties and the lack of reliable transportation also prohibit their getting to these project areas.

- Ceremonial and social dancing is an important part of Indian life. The dance arbor provides shade for the viewers and focuses attention on the dancers performing in the center of the arbor. The construction of a dance arbor at Corps projects, which could be reserved for use during the year, would greatly increase Native American visitation. Also, it would be beneficial to have arbors that could be located in more private areas for conducting private ceremonies. Native Americans would be willing to serve as advisors on arbor construction or even volunteer their labor if the Corps would decide to allow arbor construction at its projects.

- Corps project areas need to have greater flexibility time-wise. Some Corps public-use areas close earlier that Native Americans would prefer. Most Indian social dancing is held in the evening, between 7 and 11 p.m. If the Corps is interested in increasing Native American visitation, keeping public-use areas open during the evening hours is critical.

- Facilities for sports that are becoming popular among Native Americans, such as disc (Frisbee) golf and softball, should be considered in future modifications to Corps public-use areas near Native American populations.

\section{Anadarko Focus Group}

Arrangements for the focus group meeting held on June 25, 1997, at the Anadarko BIA Agency Office in Anadarko, OK, were handled by Dr. Frank Winchell of the Tulsa District and Dr. Joseph Watkins (Choctaw tribal member), regional archaeologist for the BIA. The tribes represented at this meeting were Kiowa, Cheyenne/Arapaho, Western Delaware, Fort Sill Apache, Caddo, Comanche, Wichita, Apache, and Choctaw. Three members of the U.S. Forest Service who serve as representatives on the regional 
committee for the Native American Graves Protection and Repatriation Act were in attendance; however, they did not participate in the discussion.

Prior to beginning the visioning exercise, the participants asked a series of questions that were suspicious and skeptical in tone. Past treatment by the Federal Government and the U.S. Army appeared to be the reason for this line of questioning. However, after their questions were answered, they were willing to offer information during the course of the focus group discussion. This meeting produced more discussion than any other focus group in the series. There appeared to be a wide range of educational levels among the participants, but almost all indicated strong attachment to Native American culture. The meeting lasted approximately $3 \mathrm{hr}$, during which time the group became somewhat more comfortable with the approach and the questions that were asked. This was verified by the participants' responses to the evaluation form at the conclusion of the meeting.

The primary findings of the Anadarko focus group were as follows:

- There is an extensive amount of distrust of the Federal Government and those of European descent because of how Native Americans have been treated over the last 150 years. Almost all the tribes represented at this meeting were forcibly removed from their home areas and brought to Oklahoma territory by the U.S. Army. Overcoming this distrust will be a major challenge for all Corps project managers in Indian country.

- There is limited familiarity with Corps recreation projects in western Oklahoma. It would be beneficial if a tour of Corps facilities could be conducted involving both Native Americans and Corps project personnel. The Corps should consider hosting an intertribal powwow. A large flat area and a lot of potable water would be needed. Shade trees (or an arbor), sanitary facilities, electricity, and dance areas are key for these events. Euro-Americans would be welcome to attend.

- Important recreational activities among the western tribes include stomp dancing, hunting, and the harvesting of plants and animals for religious ceremonial purposes. Camping, swimming, picnicking in large groups, dog walking, hiking in wilderness areas, attending powwows, and visiting interpretive areas/displays were also identified as important forms of recreation for Native Americans in western Oklahoma. In general, these tribes showed much less acculturation with mainstream American society in their recreational habits than the tribes of the eastern portion of the state.

- Educational displays pertaining to Native American culture, especially the use of interpretive centers and the posting of signage with Native names and references, is considered important for attracting Native American visitors to Corps projects. The use of Native Americans as interpreters and rangers is critical to increasing visitation at Corps projects.

- The construction of a fishing pier could give Native Americans the ability to fish farther into lakes, since most Native Americans in this area do not own boats. Boat rentals may be an option at some Corps projects.

- Many of the social activities are intertribal, and it is possible that the Corps could host some of the activities if they chose. It is important that these activities are conducted in areas with a lot of shade. As discussed in earlier sections, a dance arbor on Corps project land would be another valuable resource if made available for use by the tribes. 
- Native Americans camp and cook in large groups. Sufficient camping and cooking areas for these groups are needed at Corps projects, especially to accommodate groups from 100 to 200 people. Large, open fire pits should be allowed at Corps projects that have, or wish to have, Native American visitors.

- While swimming is an especially favorite activity, some safety issues are associated with some Corps swimming areas. Having safer swimming areas is a concern of Native Americans.

- Native Americans do not believe they should be required to pay day-use and camping fees at Corps projects since these are lands that were originally owned by Native American tribes. Also, there are treaties that allow Native Americans to hunt and fish over a wide area. Yet, some private properties and Corps land that fall into this area cannot be accessed by Native Americans. This has not been addressed to the satisfaction of the tribes.

\section{South Dakota Meetings}

Three focus group meetings were held in the Omaha District. The first meeting was held in Pierre, SD, on July 21, 1997, at the Governor's Inn for a group of "urban Indians" from a number of reservations in South Dakota. The second was held July 22 at Fort Thompson, at the Corps' Big Bend Dam resident office adjacent to the Crow Creek Sioux reservation. The third meeting was held on July 23 at the Youth Center of the Swift Bird community on the Cheyenne River Sioux reservation on the western shore of Lake Oahe. All three meetings were organized by Mr. David Vader, Tribal Coordinator for the Omaha District, and Ms. Jeannine Nausse of the Omaha District, and were facilitated and recorded by PMCL. The major findings and results of each focus group are presented below. The opinions expressed will be attributed to the tribes represented and not to individuals.

Detailed summary notes of each of the meetings were prepared by PMCL; copies are available from Mr. Robert Dunn, (601) 634-2380, dunnr@mail.wes.army.mil.

\section{Pierre Focus Group}

Arrangements for conducting the meeting and identifying attendees were handled by Mr. Dave Vader of the Omaha District, who coordinated with Ms. Diane Big Eagle of the Crow Creek Sioux Tribe. Ten people participated, representing the Crow Creek, Rosebud, and Yankton Sioux Tribes. All the participants were from the Pierre area or Fort Thompson.

The group members entered into a free-flowing discussion of issues surrounding the two general questions, and the tone of the meeting was constructive and enthusiastic. However, there was a range of participation from those who offered a great deal of information to those who chose to speak very little. Also, some participants departed before the focus group concluded. The meeting lasted approximately $2 \mathrm{hr}$, during which time the group appeared very comfortable with the focus group approach and the questions that were asked. This was verified by the participants' responses to the final evaluation form. The single exception was one participant, who was not convinced that the effort was of much value because, in his opinion, Native Americans do what other Americans do for recreation. 
The primary findings of the Pierre focus group were these:

- Wildlife and fish habitat should be protected and enhanced. There is a general consensus that past lake projects have spoiled the land and the water. This took away a significant amount of timber which was a critical source of shade, fuel, and habitat central to the Native American livelihood in the region. Programs to reintroduce wildlife are important because of the spiritual connotations to some Native Americans. Protection and restoration projects should continue to be part of the Corps' offering.

- A fair amount of resentment and distrust with "white men" and the U.S. Government exists. The water and electrical power supplies are substandard on many of the reservations. A portion of the money generated by hydroelectric power stations could be set aside to improve reservation infrastructure. The Native Americans are very interested in having a participatory role in future land and water management decisions. It is important that the perspectives from the "grass roots" Native Americans are clearly taken into account.

- Economic development and health are a high priority for Native Americans in the region. Corps initiatives that could bring jobs should be a priority. Present positions at Corps facilities should be filled by Native Americans, especially those where interpretation of cultural resources is addressed. Many tourists come to South Dakota to see Native Americans, so why not hire them? Future developments, like a golf course at Fort Thompson, should be operated by Native Americans.

- Native Americans enjoy many of the same recreational activities common to the American population in general. Such activities include fishing, swimming, boating, camping, hunting, gardening, and more seasonal activities such as cross-country skiing, skating, and hockey. However, due to the cost, Native Americans rarely recreate in boats, jet skis, or other expensive accessories. They were generally comfortable with this, stating that Native Americans "make do with what they have."

- Native Americans also enjoy recreating together in large gatherings called powwows. A powwow is generally held every weekend. The Corps could assist tribal members by providing the tribe with a suitable free location furnished with water, an arbor, an arena area, and camping pads for the tents. The commercial popularity of the powwows could lead to increased tourism and more jobs.

- Native Americans enjoy gathering for story-telling, primarily to pass on tribal traditions and culture. Native Americans tend to involve their youth in recreational opportunities, and much of the recreation is youth-driven. The Corps could provide a summer camp for tribal youth, especially at-risk youth. The camp could be staffed by Native Americans, which would provide economic benefit to the tribe.

- The price charged by the Corps for swimming and camping at their sites could be lowered or waived for Native Americans. Many tribal people in this region are under a great deal of social stress (poverty and unemployment). It is difficult, if not impossible, for some to afford entry fees. The idea of spending money on recreation pursuits is rather unrealistic.

\section{Fort Thompson Focus Group}

Arrangements for securing the meeting location and inviting participants were handled by Mr. Dave Vader of the Omaha District, who coordinated with Ms. Diane 
Big Eagle of the Crow Creek Sioux Tribe. All five of the participants represented the Crow Creek Sioux or were from Fort Henderson.

To begin the focus group meeting, the participants were asked to describe what they typically do for recreation and leisure, as a means of introducing themselves and understanding important issues concerning Native American recreation/leisure at Corps projects, either existing or desired. The group then entered into a free-flowing discussion of issues surrounding the two standard questions.

The participants were very cooperative, and the tone of the meeting was constructive and enthusiastic. The meeting lasted almost $2 \mathrm{hr}$, and most of the discussion centered on issues of economic development. The group appeared very comfortable with the focus group approach and the questions that were asked, as confirmed by their responses to the evaluation form.

The primary findings of the Fort Thompson focus group were:

- Native Americans engage in many types of outdoor recreation activities. Softball games and tournaments are prominent, but fishing, boating, picnicking, horseshoe tournaments, biking, and hiking were also mentioned.

- Youth are seen as the driving force behind decisions about the types of recreational activities to be pursued. There is great pride that two young Native American men work as rangers at Lake Sharpe.

- Native American powwows are an important cultural activity, but other events such as story telling, music performances, and plays would also provide opportunities for enjoyment by non-Native Americans.

- There is a perceived need for linking economic opportunities for Native Americans to recreational development.

- Corps facilities should be expanded to accommodate larger groups of Native Americans (for example, larger pavilions and more showers). The existing facilities at Lake Sharpe are well maintained, but they are small for holding powwows.

- There are some safety issues related to water-based outdoor recreation (by Native American youth) that cause concern. The Native American lifeguards at the Big Bend Dam swimming area are paid by the Crow Creek Sioux, not the Corps.

- Specific facility enhancements that were recommended by the Native American participants included nature trails, an outdoor theater, cultural museums, development for water sports, and development and maintenance of campsites.

\section{Swift Bird Focus Group}

Arrangements for this meeting were handled by Mr. Dave Vader of the Omaha District, who coordinated with Ms. Karen Nitzschke of the Cheyenne River reservation. All seven of the participants represented the Swift Bird Community.

The tone of the meeting, while generally friendly, was fairly reserved and suspicious. The participants displayed a somewhat defeated posture on their recreation opportunities in the area. The meeting lasted about $2 \mathrm{hr}$, during which time the group appeared very comfortable with the focus group approach and the questions that were asked. This was verified by the participants' responses to the evaluation form. Some 
participants came and went during the meeting (to attend to children, etc.); however, this did not appear to distract from the focus of the session.

The primary findings of the Swift Bird focus group were:

- Native Americans like the same kinds of recreational activities as other Americans. These activities include swimming, fishing, hunting, picnicking, hiking, boating, badminton, volleyball, softball, basketball, ice-skating, and sledding.

- Native Americans desire accessibility to recreational areas with proper facilities. These were defined as facilities that include a sufficient number of clean restrooms, enough tables in picnicking areas, proper trash management, safe areas for swimming that are separate from boating areas and roped off to prevent swimming in deep water, and areas fenced off to livestock.

- New developments should be built on the reservation side of the lake. It was clear that most Native Americans in this area do not have convenient access to Corps facilities. A favorite and potentially deadly recreational activity for teenagers is jumping off the Highway 212 bridge. The Corps should hire mainly Native Americans to run the new developments. A facility that offers fuel, bait, and boat rentals would be welcomed. More Native Americans should be hired at existing Corps sites, which would increase enthusiasm for Native Americans to use the sites.

- Native Americans generally do not feel comfortable around whites; they tend to believe they are discriminated against and that they are still viewed as "savages." Native Americans also feel that whites only want to profit from them and assume full control of any development that is profitable.

- Native Americans would welcome areas provided for powwows. The areas should include drinking water, showers, toilets, an arbor area for dancing, and a large cooking pit.

\section{Increasing Native American Visitation to Corps Projects}

Recommendations on making Corps facilities more Indian-friendly and increasing Native American visitation to Corps projects, based on input from all six focus groups, are summarized below.

- Respect Native Americans and their cultural values (both uniformed Corps personnel and gate attendants).

- Deal with Native Americans as individuals, not as Indian stereotypes. That is, do not assume that recreational facilities will be destroyed if they are close to a reservation or used primarily by Indians.

- Allow Native American artists to decorate Corps facilities that are being built to increase Native American visitation. (This will help deter vandalism.)

- Integrate education with recreation. That is, create interpretive programs for natural and cultural resources geared to Native American youth but available to all ages.

- Put up signs with English and Indian names when interpreting natural and cultural resources in Indian country.

- Consider hosting an annual powwow open to the public. Do not charge a fee unless it is for a good cause, such as scholarships for Native Americans. 
- Consider the construction of permanent structures that could be reserved by Native Americans for social and ceremonial dancing (for example, dance arbors, amphitheaters, and large shelters).

- Hire Native Americans as interpretive guides, rangers, lifeguards, etc. (As a result of Federal grants, many times the tribes will cost-share in providing salaries for the Native American.)

- Consider waiving day-use and camping fees in Indian country.

- Recognize that Native Americans recreate in large groups and plan accordingly in designing picnic shelters, camping areas, and sanitary facilities. Groups of 50 to 100 people are not unusual.

- Construct fishing piers on Corps lakes in areas where Native Americans have limited means to buy boats.

- Allow traditional cooking areas (open fire pits) in some public-use areas.

- Be more flexible in keeping public-use areas open at night or at least until midnight at Corps projects in Indian country.

- Construct some land-based facilities to attract more Native American visitors. Indian youth love all sports, but especially basketball and softball, which require the construction and maintenance of facilities.

- Design public-use areas so that swimming and picnic areas should have adequate shade.

- Place literature on upcoming powwows or other events important to Native Americans in the resident office or visitor center at Corps projects in Indian country.

\section{Implications for Corps Operations}

Executive Order 12862, issued September 11, 1993, requires Federal Agencies to identify the customers who are, or should be, served by the agency and to survey customers to determine the kind and quality of services they want and their level of satisfaction with existing services. The purpose of developing information on customer satisfaction is to set standards that will allow Federal agencies to "provide service to the public that matches or exceeds the best service available in the private sector."

Executive Order 12898, issued February 11, 1994, directs Federal agencies to "identify differential patterns of consumption of natural resources among minority populations and low-income populations" and ensure that programs, policies, or activities that substantially affect human health of the environment (including, presumably, outdoor recreation operations) do not exclude persons from receiving the benefits of such programs as a result of race, color, or national origin. Furthermore, each Federal agency is ordered to, whenever practicable, collect, maintain, and analyze information on the race and national origin of residents of areas surrounding Federal facilities or sites that have substantial environmental, human health, or economic effects on nearby populations (Gramann 1996).

The Corps of Engineers has set in motion a research effort to comply with the requirements of these Executive Orders. The information on Native American recreation summarized in this technical note may be regarded as first step toward compliance in at least two ways. First, the limited scope of data acquisition among this particular 
ethnic group makes it a first step toward understanding Native American recreation habits and preferences. The desert Southwest, the North Pacific, and the North Central United States are all uninvestigated areas in which considerable numbers of Native Americans reside and recreate. Second, the task of acquiring data and implementing change will have to be a long-term process for the Corps and other Federal land management agencies since Native Americans constitute only the first of four ethnic minority groups that will be studied.

Compliance with the Executive Orders will involve changes in the way the Corps currently interacts with its ethnic minority customers. Recommended changes to make Corps operational projects more Indian-friendly can be grouped into three general areas: facilities, management, and policy.

The following recommendations are those proposed by the Native American participants of the six focus groups.

- Changes to facilities: construct and maintain dance arbors, interpretive trails for both natural and cultural resources, amphitheaters for holding Native American cultural events, outdoor basketball courts, softball fields/diamonds, fishing piers, larger picnic shelters and sanitary facilities, and larger changing facilities near swim beaches.

- Managerial changes: periodically sponsor intertribal powwows, keep certain public-use areas at Corps projects open during the evening hours, hire Native Americans as fulltime and part-time/seasonal employees, use Native Americans as lifeguards at swimming areas frequented by Native American children, insist on the courteous treatment of Native American visitors by "Mom and Pop" gate attendants as well as uniformed Corps personnel, actively seek input from Native Americans in the design and construction of all facilities built to increase Native American visitation, and use Native American artists to decorate such facilities.

- Policy changes at higher levels of authority within the Corps: waive all user fees at Corps projects near large populations of low-income Native Americans, cost-share with tribes on facilities constructed primarily for use by Native Americans, and enforce regulations to ensure complete parity in the design quality and the maintenance of Corps public-use areas that receive primarily Native American, rather than EuroAmerican, visitation.

One of the goals of the RRP's Ethnic Culture work unit is to provide a survey instrument that can be used by Corps project managers, lake managers, rangers, etc., to acquire local data on the use of their projects by ethnic minority groups. The acquisition of data on minority recreation experiences and preferences through the use of surveys is essential to the Corps' future improvement in providing services to minority groups.

Based on experience gained during the focus group meetings, several recommendations have been developed with regard to the use of surveys with Native Americans. First, data acquisition among Native Americans will be most effective when it comes in the form of dialogue, rather than the administration of a survey instrument. Do not design anything, modify any existing facility, or change any aspect of current management without entering into a dialogue with Native American project users. Second, do not promise what you cannot deliver. There is no better way to destroy your credibility. Native Americans already harbor a great deal of suspicion and distrust of Federal agencies and the Corps of Engineers, in particular. Third, do not be afraid to 
start small. The improvement of services and facilities for minority users will have to be an incremental process consisting of very small steps over a long period of time. While it is true that Native Americans have "learned to make do," it is also true that they deserve better.

\section{Levels of Acculturation Among Native Americans}

Gramann (1996) notes that, in North America, sociological research on cultural assimilation (or acculturation) has been guided by three competing ideologies: Anglo-conformity, the melting pot model, and cultural pluralism. He argues that the Anglo-conformity and melting pot models seem inappropriate for understanding ethnic differences in outdoor recreation. The consensus of recreation researchers now appears to be that leisure behavior remains both individually and culturally expressive. Even with immigrant groups who quickly adopt those traits of mainstream American culture that have special worth for advancing socioeconomically, over time, leisure activities can remain an important arena in which traditional ethnic values are maintained and expressed (Gramann 1996). McDonald and McAvoy (1997) have also noted that certain pan-Indian worldview elements may be reflected as well in behavioral and attitudinal differences in leisure (for example, the sacredness of all things, the inseparableness from nature, the strong sense of place, the cyclical nature of existence, and the importance of the spoken word).

Generally, the discussions from the six Native American focus groups bear this out. Native American recreation taken as a whole is distinctly different from mainstream Euro-American recreation habits. However, we should not view recreation in Indian country as homogeneous or monolithic in nature. Clearly, there are important differences between the recreation habits of the five "civilized tribes" now residing in eastern Oklahoma and the recreation habits of the Sioux living on reservations in South Dakota. There appear to be different levels of acculturation which must be recognized if we are to make any headway in making Corps facilities more Indian friendly. The use of focus groups or survey instruments may be critical to discover these levels, when planning improvements in recreational facilities at Corps projects. Indeed, one of the objectives of the Ethnic Culture work unit is to provide the Corps with a survey instrument that could be used by Corps project managers interested in improving or attracting ethnic minority visitation.

Within the sphere of leisure research, the favored model for understanding observed differences among different ethnic groups is a variation of the cultural pluralism model known as "selective acculturation" (Gramann 1996). The basic hypothesis, largely derived from work among Hispanics, is that because ethnic minorities are not culturally undifferentiated blocs, their recreation behaviors and styles will vary as a function of their degree of assimilation into Anglo culture. Members of ethnic minorities will become more Anglo-like in their recreation with increasing degrees of assimilation. Assimilation in this research is measured by generational tenure (number of generations in the United States) and the degree of language acculturation. Another aspect of the model is the notion of core cultural values, which would tend to resist assimilation into the mainstream culture for longer periods of time. Because recreation/leisure behavior has this expressive nature, the core values of the group might be preserved for longer periods of time. 
Does the selective acculturation model fit what we have learned about Native American recreation? Highly acculturated groups such as the "civilized tribes" of eastern Oklahoma fit the model quite well. Their contact with Euro-Americans can be measured in centuries and their dress, bilingual abilities, and economic success indicate a high degree of acceptance of Euro-American culture. However, their core cultural values are largely retained in their social and ceremonial dancing, their preference for recreating in large groups, and their strong desire to preserve their language and culture for future generations. They have selectively taken the aspects of Euro-American culture needed for socioeconomic success while keeping their inner core values intact. Recreation and leisure behavior expresses those core values, allows the groups to externalize them, and provides a mechanism for their intergenerational transmission.

Native Americans in the western United States are experientially still too close to the Indian wars of the late 19th century. Many of the people who participated in the focus groups had grandparents who were killed or forced onto reservations by the U.S. Army. The suspicious questioning the WES team encountered in western Oklahoma was a striking manifestation of an ongoing "red versus white" ideological struggle. Not only are core cultural values largely intact among the least acculturated Native American groups, but there is also a strong resistance to knuckling under to the laws and regulations of the dominant society (see summary notes on the Anadarko focus group). Too little time and too much spilled blood are major obstacles to their easy assimilation into the dominant culture. These people do not want to be white men in red skins, nor should they.

The Native Americans who participated in the six focus groups clearly felt uncomfortable and, in some cases, unwelcome at Corps facilities that were visited primarily by Euro-Ameri cans. The question of acculturation and perceived discrimination is one which Gramann (1996) addresses and one that the Corps must come to terms with, as an agency providing public access to recreation facilities. Perceived discrimination has mostly been viewed in recreation research as an independent variable that affects recreation participation. People who feel unwelcome will usually not come back; discrimination reduces visitation by minority groups. Gramann notes that the perception of discrimination can also be treated as a dependent variable that is influenced by a variety of socioeconomic factors. One such factor is the level of cultural assimilation or acculturation. The question of interest to researchers is whether minority group members with differing levels of acculturation also differ in their perception of discrimination of recreation areas.

One response to this question is the ethnic enclosure hypothesis which is based on Gordon's (1964) theory of ethnic assimilation. His hypothesis predicts that greater cultural assimilation will lead to reduced levels of perceived discrimination by minority group members. A contrasting perspective on the issue is known as the ethnic competition hypothesis. Glazer and Moynihan (1963) argued that increased knowledge of the dominant culture and its higher socioeconomic standing will lead to greater perceptions of discrimination.

Do the findings of the six focus groups shed any light on this debate? The eastern Oklahoma tribes appear to lend support to the ethnic enclosure hypothesis. Their greater knowledge of the dominant culture, their friendship and kinship ties with Euro-Americans, and their relative affluence and social mobility allow them to feel greater acceptance into mainstream American society. They appear to perceive less 
discrimination. Consequently, they use available Corps facilities and welcome changes that would make them even more Indian friendly.

Among the tribes of western Oklahoma and the Sioux tribes in South Dakota, the ethnic competition hypothesis seems a more plausible explanation for the responses. Due to the pervasive influence of television, even Native Americans on the most remote reservation have a window into the material affluence of the dominant culture. Their heightened awareness of racial and cultural differences may be causing an increased perception of discrimination. They are reluctant to cross the river and use facilities enjoyed by the dominant culture because it exposes them to the possibility of discrimination. Their shared perception of discrimination causes feelings of ethnic group solidarity and results in a form of boundary maintenance, expressed as "Let the whites stay on their side of the river. Just improve the facilities on our side."

\section{Research Needs}

McDonald and McAvoy (1997) have identified seven areas for future leisure research among Native Americans. These researchers recommend that "future research should be designed to

(1) Identify causal factors for leisure behaviors among Native Americans through exploratory qualitative research.

(2) Further explore the literature concerning pan-Indian traits and values that may be reflected in behavioral and attitudinal differences in leisure.

(3) Develop qualitative methods to further define Native American worldview elements.

(4) Utilize the anthropological study of play and outdoor activities, in such a way as to make them meaningful within leisure study constructs, e.g., creation of behavioral models.

(5) Critically examine the postulate that Native Americans have a special bond to the land and how an activity's setting may override the activity (including leisure) due to the person's relationship to the setting.

(6) Conduct more descriptive research efforts on Native American leisure.

(7) In future research, take into account the historical relationships between aboriginal peoples and both government and the research community."

While some of these research areas fall outside the pragmatic concerns of the Corps, the qualitative descriptive data that were acquired during the focus group meetings should prove useful to other researchers investigating areas 1,3 , and 6 . However, a great deal more research needs to be done for Native Americans and for other ethnic minority groups. Over the next 2 fiscal years, more data will be acquired, and our understanding of minority recreation should increase exponentially. In this broader context, Gramann (1996) identified five applied research gaps that will be carefully considered in future research for the Ethnic Culture work unit: 
(1) More information is needed on the recreational behaviors and styles of minority group visitors to water-based outdoor recreation areas.

(2) There is a particular scarcity of data on the outdoor recreation behaviors, styles, and constraints on Asian Americans.

(3) More research is needed on perceived discrimination as a cause of underutilization of recreation areas by minority group members.

(4) Changes in the ethnic composition of the visitor population appear to be producing displacement and avoidance effects in some recreation areas. More research is needed on where displaced recreationists go as an alternative.

(5) There is a need to rigorously evaluate the effectiveness of different means of oral or written communication among ethnic minorities in promoting rule awareness and obedience at outdoor recreation sites. Previous research among Euro-Americans has generally shown "communication-based management" to be effective in reducing many rule violations.

\section{Summary}

Fifteen Native American tribes in the Tulsa and Omaha Districts participated in the six focus group meetings conducted for the Corps' Recreation Research Program during the summer of 1997. The participants constitute a representative cross section of Native American experiences at Corps projects and of their preferences for outdoor recreation. Based on the findings of these focus groups, a number of characteristics of Native American recreation have been identified which could have important management implications for Corps decision-makers. These characteristics and their implications to the Corps [italicized within brackets] are as follows:

- Larger recreational group size than typical Euro-American families [design and build facilities to handle these large groups].

- Greater emphasis on educational and interpretive programs as part of the recreation experience [create or expand existing interpretive programs].

- Greater perceived discrimination among the least acculturated groups [be proactive in curtailing racist behavior among Corps employees or contractors].

- Greater use of facilities during the evening hours [allow greater flexibility in providing access to some public-use areas, such as nighttime use].

- Financial hardship prohibiting use of Corps facilities [investigate the waiving of user fees for projects near low-income Native American populations].

- High unemployment and feeling of alienation from mainstream American society [actively recruit Native Americans as full-time and part-time employees and make better use of available volunteer labor].

- Desire for facilities that are more Indian friendly [consult with Native Americans in the design and construction of arbors, nature trails, amphitheaters, etc.]. 


\section{References}

Glazer, N., and Moynihan, D. (1963). Beyond the melting pot. MIT and Harvard University Press, Cambridge, MA.

Gordon, M. (1964). Assimilation into American life: The role of race, religion, and national origins. Oxford University Press, New York.

Gramann, J. H. (1996). “Ethnicity, race, and outdoor recreation: A review of trends, policy, and research," Miscellaneous Paper R-96-1, U.S. Army Engineer Waterways Experiment Station, Vicksburg, MS.

Krueger, R. A. (1988). Focus groups: A practical guide for applied research. Sage Publications, Inc., Newbury Park, CA.

McDonald, D., and McAvoy, L. (1997). "Native Americans and leisure: State of the research and future directions," Journal of Leisure Research 29(2), 145-66.

\section{Point of Contact}

For additional information concerning this technical note, contact Mr. Robert A. Dunn, U.S. Army Engineer Waterways Experiment Station, (601) 634-2380, dunnr@ mail.wes.army.mil. 